Istanbul Finance Congress, November 1-2, 2018, Istanbul, Turkey.

\title{
FOREIGN TRADE ANALYSIS OF DENIZLI PROVINCE
}

\author{
DOI: 10.17261/Pressacademia.2018.984 \\ PAP-IFC- V.8-2018(16)-p.71-75
}

\section{Aysun Karadayi}

Pamukkale University, Management Department, Denizli, Turkey. aysun.karadayi@gmail.com, ORCID: 0000-0002-0485-5773

\section{To cite this document}

Karadayi, A. (2018). Foreign trade analysis of Denizli province. PressAcademia Procedia (PAP), V.8, p.71-75.

Permanant link to this document: http://doi.org/10.17261/Pressacademia.2018.984

Copyright: Published by PressAcademia and limited licenced re-use rights only.

\section{ABSTRACT}

Purpose- In this study, for the period 2012-2016, foreign trade data on Denizli and Turkey basis were examined and provincial and countrylevel evaluations were carried out by the comparison method.

Methodology- The export and import concentration ratios for Denizli were calculated and subsequently market and sectoral concentration conditions on the provincial level were evaluated. In addition, export and import concentration coefficients for Denizli were calculated and the sectors that are prominent in provincial foreign trade were determined.

Findings- The results showed that even though fluctuations in the period examined, Denizli has a certain foreign trade trend and that the sectoral concentration in the foreign trade of the province is higher than the market concentration of it.

Conclusion- Sectoral concentration may not be considered as a negative situation if it is derived from a real specialization in the concentrated sectors and thus high value-added production. The production and export strategy of the province can be established both on the basis of increasing the value-added in certain sectors and also on increasing the sector and product diversity in production and export.

Keywords: Denizli, concentration ratio, concentration coefficient, market concentration, sectoral concentration. JEL Codes: F10, F14, O24

\section{DENizLi íLi DIŞ TiCARET ANALIZi}

\section{ÖZET}

Amaç- Bu çalışmada 2012-2016 dönemi için Denizli ve Türkiye bazında dış ticaret verileri incelenmiştir ve il ve ülke düzeyinde karşılaştırma yöntemi ile değerlendirmeler yapılmıştır.

Yöntem- Denizli ili için ihracat ve ithalat yoğunlaşma oranları hesaplanarak pazar ve sektörel yoğunlaşma durumları değerlendirilmiştir. Ayrıca ihracat ve ithalat yoğunlaşma katsayıları hesaplanarak il dış ticaretinde öne çıkan sektörler tespit edilmiştir.

Bulgular- Ulaşılan sonuçlar incelenen dönemde dalgalanmalar olsa da Denizli'nin belli bir dış ticaret eğilimine sahip olduğunu ve il dış ticaretinde sektörel yoğunlaşmanın pazar yoğunlaşmasından daha yüksek olduğunu göstermiştir.

Sonuç- Sektörel yoğunlaşma eğer yoğunlaşılan sektörlerde gerçek bir uzmanlaşma olmasından ve bu sayede yüksek katma değerli üretim yapılmasından kaynaklanıyorsa olumsuz bir durum olarak değerlendirilmeyebilir. İlin üretim ve ihracat stratejisi belli sektörlerde katma değer artışı sağlanması üzerine kurulabileceği gibi üretim ve ihracatta sektör ve ürün çeşitliliğinin artırılması üzerine de kurulabilir.

Anahtar Kelimeler: Denizli, yoğunlaşma oranı, yoğunlaşma katsayısı, pazar yoğunlaşması, sektörel yoğunlaşma. JEL Kodları: F10, F14, O24

\section{GiRiş}

Yoğunlaşma Analizi bölgelerin ekonomik faaliyetler yönünden karşılaştırılması ve göreli olarak uzmanlaştığı sektörlerin tespitinde kullanılmaktadır. Daha çok bölgesel iktisat çalışmalarında yaygınlıkla kullanılan Analiz ile bölgelerin sektör düzeyinde mukayeseli üstünlükleri ortaya konulabilmektedir (Bayraktutan vd., 2012; Çamlıca vd., 2016; İskenderoğlu,2017; Sungur, 2015)

Yoğunlaşma oranı veya katsayısı, kolay hesaplanması özelliği nedeni ile bu analizde yaygın olarak kullanılan yoğunlaşma ölçüleridir. Dış ticarette yoğunlaşma oranı esas olarak, belli sayıdaki firma, ürün, sektör veya ülkenin toplam paylarını ifade eden bir kavramdır. Yoğunlaşma oranı “0 ile 100" arasında bir değer almakta ve aşağıda belirtilen formül yardımıyla hesaplanmaktadır. Formülde, $\mathbf{C R}_{\mathbf{m}}$ yoğunlaşma oranını, $\mathbf{P}_{\mathbf{i}}$ ise firma, ürün, sektör veya ülkenin payını göstermektedir (Erka vd., 2016: 1831; Kaynak vd., 2011:47).

$$
\mathrm{CR}_{\mathrm{m}}=\sum_{\mathrm{i}=1}^{\mathrm{m}} \mathbf{P}_{\mathrm{i}} * 100
$$


İhracat (veya ithalat) yoğunlaşma katsayısı ise il sektör ihracatının (veya ithalatıın) il toplam ihracatındaki (veya ithalatındaki) payının, sektörün ülke toplam ihracatındaki (veya ithalatındaki) payına oranlanması ile hesaplanmaktadır ve sektörün ülke ihracatındaki (veya ithalatındaki) göreli üstünlüğünü ifade etmektedir. İl ihracat (ithalat) yoğunlaşma katsayısı (PECR) ise aşağıda gösterilen formül yardımıyla hesaplanmaktadır (GEKA, 2018: 85-86).

$$
\operatorname{PECR}=\left(\mathbf{X}_{\mathrm{IJ}} / \mathbf{X}_{\mathrm{I}}\right) /\left(\mathbf{X}_{\mathrm{J}} / \mathbf{X}\right)
$$

$\mathbf{X}_{\mathrm{IJ}}$ : i ilinde j sektörünün ihracatı (ithalatı)

$\mathbf{X}_{\mathrm{I}}$ : i ilinin toplam ihracatı (ithalatı)
$\mathbf{X}_{\mathbf{I}}$ : Türkiye'deki j sektörünün toplam ihracatı (ithalatı)

$\mathbf{X}$ : Türkiye'nin toplam ihracatı (ithalatı)

Katsayının 1'den büyük olması durumunda sektörün öne çıktığı ve uzmanlaşmanın söz konusu olduğu ifade edilir. Yoğunlaşma oranı ve katsayısı genellikle istihdam verileri kullanılarak hesaplansa da üretim, katma değer, ihracat (veya ithalat) verileri kullanılarak da hesaplanabilmektedir (Sungur, O., 2015: 323).

\section{VERI VE BULGULAR}

\subsection{Genel Dış Ticaret Görünümü}

2016 yılında Denizli'de 737 milyon USD dış ticaret fazlası verilmiştir; 2,4 milyar USD ihracat, 1,6 milyar USD ithalat yapılmıştır. Aynı yıl, Türkiye genelinde ise 56 milyar USD dış ticaret açığı verilmiştir; toplam 142 milyar USD ihracat, 198 milyar USD ithalat yapılmıştır.

Tablo 1: Dış Ticaretin Gelişimi (Milyon USD)

\begin{tabular}{|c|c|c|c|c|c|c|}
\hline \multirow{2}{*}{ Yıllar } & \multicolumn{3}{|c|}{ Denizli } & \multicolumn{3}{|c|}{ Türkiye } \\
\hline & İhracat & ithalat & Denge & İhracat & ithalat & Denge \\
\hline 2012 & 2.623 & 2.262 & 360 & 152.461 & 236.545 & -84.083 \\
\hline 2013 & 2.741 & 2.208 & 533 & 151.802 & 251.661 & -99.858 \\
\hline 2014 & 2.815 & 2.177 & 639 & 157.610 & 242.177 & -84.566 \\
\hline 2015 & 2.516 & 1.902 & 614 & 143.838 & 207.234 & -63.395 \\
\hline 2016 & 2.403 & 1.666 & 737 & 142.529 & 198.618 & -56.088 \\
\hline Yıllık Ort. Artış (\%) & $-1,97$ & $-7,21$ & 20,99 & $-1,67$ & $-4,27$ & $-9,63$ \\
\hline
\end{tabular}

Kaynak: TÜiK, Dış Ticaret İstatistikleri

Türkiye toplam dış ticaretinin aksine Denizli dış ticaret fazlası vererek ülke ekonomisine katkı sağlamaktadır. 2012 - 2016 döneminde Denizli'de ihracattaki yıllık ortalama \%1,97 azalışa karşın ithalatta \%7,2 düşüş gerçekleşmesi dış ticaret fazlasının artmasına yol açmıştır. Türkiye genelinde ise son yıllarda ithalatta meydana gelen düşüş ihracatta meydana gelen düşüşten daha fazla olduğu için dış ticaret açığı azalmıştır; ihracattaki ortalama \%1,6 oranındaki düşüşe karşın ithalat \%4,2 oranında azalmıştır.

Denizli ihracatı ana sektörler itibariyle incelendiğinde, il ihracatında başı çeken ana sektörün imalât sanayii olduğu görülmektedir. İmalât sanayi ihracatı son üç senede \%15 oranında gerileme gösterse de, ilin toplam ihracatının yaklaşık \%96'sını oluşturmaktadır. İlde 2016 yılı itibariyle dış ticaret fazlasının \%97'si imalât sanayiinden kaynaklanmaktadır. Denizli ithalatı ana sektörler itibariyle incelendiğinde, ihracatta olduğu gibi ithalatta da başı çeken sektör imalât sanayiidir. İmalât sanayii ithalatı, il toplam ithalatının yaklaşık \%95'ini kapsamaktadır. Yıllar itibariyle il ihracat ve ithalatının ana sektörlere göre dağılımı aşağıdaki tabloda verilmiştir.

Tablo 2: Denizli ili İhracat ve İthalatının Ana Sektörlere Göre Dağılımı (Milyon USD)

\begin{tabular}{|c|c|c|c|c|c|c|c|c|c|}
\hline \multirow{2}{*}{ ISIC AdI } & \multicolumn{3}{|c|}{ İhracat } & \multicolumn{3}{|c|}{ ithalat } & \multicolumn{3}{|c|}{ Dış Ticaret Dengesi } \\
\hline & 2014 & 2015 & 2016 & 2014 & 2015 & 2016 & 2014 & 2015 & 2016 \\
\hline Tarım, Ormancılık ve Balıkçılık & 44 & 44 & 47 & 106 & 115 & 72 & -67 & -76 & -25 \\
\hline Madencilik ve Taşocakçılığı & 60 & 46 & 57 & 0 & 17 & 7 & 60 & 29 & 50 \\
\hline İmalât Sanayi & 2.711 & 2.426 & 2.299 & 2.061 & 1.770 & 1.587 & 650 & 656 & 712 \\
\hline Toplam & 2.815 & 2.516 & 2.403 & 2.167 & 1.902 & 1.666 & 648 & 614 & 737 \\
\hline \multicolumn{10}{|c|}{ Yüzde Dağılım (\%) } \\
\hline Tarım, Ormancılık ve Balıkçılık & 1,56 & 1,75 & 1,96 & 4,89 & 6,05 & 4,32 & $-9,57$ & $-11,56$ & $-3,39$ \\
\hline Madencilik ve Taşocakçılığı & 2,13 & 1,83 & 2,37 & 0,01 & 0,89 & 0,42 & 9,22 & 4,72 & 6,78 \\
\hline İmalât Sanayi & 96,31 & 96,42 & 95,67 & 95,10 & 93,06 & 95,26 & 100,35 & 106,84 & 96,61 \\
\hline
\end{tabular}

Kaynak: TÜiK, Dış Ticaret İstatistikleri

\subsection{Pazar Yoğunlaşma Oranı ìle î Dış Ticaretinin Analizi}

Denizli, 2016 yılı itibariyle toplam 180 ülkeye ihracat yapmıştır. İhracatın büyük kısmı Avrupa ülkeleri ve ABD’yi kapsamaktadır. Başlıca en çok ihracat yapılan ülkeler, Almanya, İngiltere ve ABD'dir. Ülke yoğunlaşma oranı anlamına gelen CR değerinin ihracat kaleminde yüksek 
olması, ihracatın az sayıda ülkeye yapıldığı anlamına gelmektedir. İlde en çok ihracatın yapıldığı ilk dört ülkenin payını gösteren CR $\mathbf{4}$ değeri \%37 olarak gerçekleşmiş olup bu oran orta derecede pazar yoğunlaşması olduğunu göstermektedir.

2016 yılı itibariyle Denizli ithalat verileri incelendiğinde, ithalatta en büyük payın Rusya Federasyonu'na ait olduğu görülmektedir. illin en çok ithalat yaptığı ilk dört ülkenin payını gösteren $\mathbf{C R}_{\mathbf{4}}$ değeri, 2016 yılında \%50 olarak gerçekleşmiş olup bu oran yüksek derecede pazar yoğunlaşması olduğunu göstermektedir. Hesaplanan yoğunlaşma oranları Denizli ihracat pazarının birkaç ülkeye bağlı olmadığını ve ithalat pazarının, ihracat pazarına göre daha dar olduğunu göstermektedir.

Tablo 3: Denizli ili İhracat ve İthalatının Ülkelere Göre Dağılımı (2016)

\begin{tabular}{|c|c|c|c|c|c|c|c|c|}
\hline \multirow[b]{2}{*}{$\mathrm{CR}_{\mathrm{i}}$} & \multirow[b]{2}{*}{ Ülke } & \multicolumn{2}{|c|}{ İhracat } & \multirow[b]{2}{*}{$\begin{array}{r}\mathrm{CR}_{\mathrm{i}} \\
\text { Oranı } \\
(\%)\end{array}$} & \multirow[b]{2}{*}{ Ülke } & \multicolumn{2}{|c|}{ Ithalat } & \multirow[b]{2}{*}{$\begin{array}{r}\text { CR } \\
\text { Oranı } \\
(\%)\end{array}$} \\
\hline & & $\begin{array}{c}\text { Milyon } \\
\text { USD }\end{array}$ & Pay (\%) & & & $\begin{array}{c}\text { Milyon } \\
\text { USD }\end{array}$ & Pay (\%) & \\
\hline $\mathrm{CR}_{\mathbf{1}}$ & Almanya & 268 & 11,2 & 11,2 & Rusya Fed. & 285,6 & 17,1 & 17,1 \\
\hline CR2 & İngiltere & 240 & 10,0 & 21,1 & Kazakistan & 275,1 & 16,5 & 33,7 \\
\hline $\mathrm{CR}_{3}$ & $\mathrm{ABD}$ & 198,3 & 8,3 & 29,4 & Özbekistan & 145,9 & 8,8 & 42,4 \\
\hline $\mathrm{CR}_{4}$ & İtalya & 174,1 & 7,2 & 36,6 & Çin & 132,4 & 7,9 & 50,4 \\
\hline $\mathbf{C R}_{5}$ & Fransa & 119,5 & 5,0 & 41,6 & Türkmenistan & 83,3 & 5,0 & 55,4 \\
\hline $\mathrm{CR}_{6}$ & İsrail & 104,2 & 4,3 & 45,9 & Ukrayna & 81,9 & 4,9 & 60,3 \\
\hline $\mathrm{CR}_{7}$ & Hollanda & 98,8 & 4,1 & 50,1 & Almanya & 61,7 & 3,7 & 64,0 \\
\hline $\mathrm{CR}_{8}$ & Romanya & 70,2 & 2,9 & 53,0 & $\mathrm{ABD}$ & 58,1 & 3,5 & 67,5 \\
\hline \multirow[t]{2}{*}{ CR, } & İspanya & 54,7 & 2,3 & 55,3 & İspanya & 56,7 & 3,4 & 70,9 \\
\hline & Toplam & 2.403 & 100,0 & & Toplam & 1.666 & 100,0 & \\
\hline
\end{tabular}

Kaynak: TÜiK, Dış Ticaret İstatistikleri

\subsection{Sektörel Yoğunlaşma Oranı ile î Dış Ticaretinin Analizi}

Alt sektörlere göre dağılıma bakıldığında Denizli ihracatında, Tekstil Ürünleri sektörü ilk sırada yer almaktadır. Sektör ihracatı 2014 yılında 921 milyon USD’nin üstüne çıksa da 2015 yılında 824 milyon USD seviyesine gerilemiş ardından 2016 yılında 915 milyon USD seviyesine çıkmıştır. Ana Metal Sanayi, Giyim Eşyası ve Metal Eşya Sanayi sektörlerinde ihracat sürekli bir azalış trendine girmiştir ve sırasıyla \%34, \%12 ve \%38 düzeylerinde azalış gerçekleşmiştir. Diğer yandan Taşocakçılığı ve Diğer Madencilik, Tarım ve Hayvancılık ile Gıda Ürünleri ve İçecek sektörlerinde sürekli bir artış trendi oluşmuştur ve sırasıyla \%75, \%33 ve \%13 düzeylerinde artış gerçekleşmiştir.

2012 ve 2016 yılları için Denizli ihracatında ilk 4 sektörün toplam payını gösteren $\mathbf{C R}_{\mathbf{4}}$ değerleri sırasıyla \%77 ve \%76 olarak gerçekleşirken, ilk 8 ülkenin toplam payını gösteren $\mathbf{C R}_{\mathbf{8}}$ değerleri sırasıyla \%95 ve \%94 olarak hesaplanmıştır. \%70'in üzerindeki CR değerleri çok yüksek derecede yoğunlaşma olduğunu gösterir ve bu durum bir taraftan o ilin o sektörlerde uzmanlaştığını gösterirken diğer taraftan ilin o sektörlere bağımlı olduğu anlamına gelir.

Tablo 4: Denizli İhracatının Alt Sektörlere Göre Dağılımı (\%)

\begin{tabular}{|c|c|c|c|c|c|c|}
\hline \multirow[b]{2}{*}{$\mathrm{CR}_{\mathrm{i}}$} & \multicolumn{2}{|l|}{2012} & \multirow[b]{2}{*}{$\begin{array}{l}C R_{i} \\
(\%)\end{array}$} & \multicolumn{2}{|l|}{2016} & \multirow[b]{2}{*}{$\begin{array}{l}C R_{i} \\
(\%)\end{array}$} \\
\hline & ISIC Adı & $\begin{array}{l}\text { Pay } \\
(\%)\end{array}$ & & ISIC Adı & $\begin{array}{l}\text { Pay } \\
(\%)\end{array}$ & \\
\hline $\mathbf{C R}_{1}$ & Tekstil Ürünleri & 33,0 & 33,0 & Tekstil Ürünleri & 38,1 & 38,1 \\
\hline $\mathbf{C R}_{\mathbf{2}}$ & Ana Metal Sanayi & 19,8 & 52,8 & Ana Metal Sanayi & 14,2 & 52,3 \\
\hline $\mathbf{C R}_{\mathbf{3}}$ & Giyim Eşyası & 13,6 & 66,4 & Giyim Eşyası & 13,0 & 65,3 \\
\hline $\mathrm{CR}_{4}$ & B.Y.S. Elektrikli Makina ve Cihazlar & 10,3 & 76,6 & B.Y.S. Elektrikli Makina ve Cihazlar & 10,3 & 75,6 \\
\hline $\mathbf{C R}_{5}$ & Metal Eşya Sanayi & 9,2 & 85,9 & Metalik Olm. Diğ. Mineral Ürünler & 6,7 & 82,3 \\
\hline $\mathbf{C R}_{6}$ & Metalik Olm. Diğ. Mineral Ürünler & 5,4 & 91,3 & Metal Eşya Sanayi & 6,2 & 88,5 \\
\hline $\mathbf{C R}_{7}$ & Gıda Ürünleri ve İçecek & 2,1 & 93,4 & Gıda Ürünleri ve İçecek & 2,8 & 91,3 \\
\hline $\mathbf{C R}_{8}$ & B.Y.S. Makine ve Teçhizat & 1,5 & 94,9 & Taşocakçılığı ve Diğer Madencilik & 2,4 & 93,7 \\
\hline $\mathbf{C R}_{\mathbf{9}}$ & Tarım ve Hayvancılık & 1,3 & 96,3 & Tarım ve Hayvancılık & 2,0 & 95,6 \\
\hline $\mathrm{CR}_{10}$ & Taşocakçılığı ve Diğer Madencilik & 1,2 & 97,5 & B.Y.S. Makine ve Teçhizat & 1,5 & 97,1 \\
\hline
\end{tabular}

Kaynak: TÜiK, Dış Ticaret İstatistikleri

Denizli ithalatında, alt sektörlere göre dağılıma bakıldığında Ana Metal Sanayi sektörünün ilk sırada yer aldığı görülmektedir. Sektör ithalatı, il toplam ithalatının 2016 yılında \%61'ini oluşturmaktadır. Pek çok sektörde ithalat tutarının 2016 yılında 2012 yılına göre azaldığı görülmekle beraber B.Y.S. Elektrikli Makine ve Cihazlar ile Ağaç ve Mantar Ürünleri sektörleri ithalat tutarlarında artış meydana geldiği görülmektedir; söz konusu artış sırasıyla \%68 ve \%31 düzeylerindedir. En fazla düşüşün Kok Kömürü, Rafine Edilmiş Petrol Ürünleri ve Nükleer Yakıtlar sektörü ile Gıda Ürünleri ve İçecek sektörü, Kâğıt ve Kâğıt Ürünleri sektörlerinde meydana gelmiş olması dikkat çekicidir; 
söz konusu azalış sırasıyla \%166, \%122 ve \%99 düzeylerindedir. Kok Kömürü, Rafine Edilmiş Petrol Ürünleri ve Nükleer Yakıtlar sektörü ithalatındaki azalışı Denizli'de doğalgaz kullanımının yaygınlaşmasına bağlamak yanlış olmayacaktır.

Denizli ithalatında 2012 ve 2016 yılları için ilk 4 sektörün toplam payını gösteren CR $_{\mathbf{4}}$ değerleri sırasıyla \%87 ve \%85 olarak gerçekleşirken, ilk 8 ülkenin toplam payını gösteren $\mathbf{C R}_{\mathbf{8}}$ değerleri sırasıyla \%96 ve \%95 olarak hesaplanmıştır. \%70'in üzerindeki CR değerleri çok yüksek derecede yoğunlaşma olduğunu gösterir ve bu durum o sektörlerdeki ürünlerin tedarikinde sıkıntı yaşanması halinde o ilin ekonomisinin zarar görebileceği anlamına gelir.

\section{Tablo 5: Denizli İthalatının Alt Sektörlere Göre Dağılımı (\%)}

\begin{tabular}{|c|c|c|c|c|c|c|}
\hline \multirow[b]{2}{*}{$\mathrm{CR}_{\mathrm{i}}$} & \multicolumn{3}{|l|}{2012} & \multicolumn{3}{|l|}{2016} \\
\hline & ISIC Adı & $\begin{array}{l}\text { Pay } \\
(\%)\end{array}$ & $\begin{array}{l}C R_{i} \\
(\%)\end{array}$ & ISIC Adı & $\begin{array}{l}\text { Pay } \\
(\%)\end{array}$ & $\begin{array}{l}C R_{\mathrm{i}} \\
(\%)\end{array}$ \\
\hline $\mathbf{C R}_{\mathbf{1}}$ & Ana Metal Sanayi & 65,6 & 65,6 & Ana Metal Sanayi & 60,7 & 60,7 \\
\hline $\mathbf{C R}_{\mathbf{2}}$ & Tekstil Ürünleri & 11,0 & 76,6 & Tekstil Ürünleri & 12,7 & 73,4 \\
\hline $\mathrm{CR}_{3}$ & Kimyasal Madde ve Ürünler & 6,1 & 82,7 & Kimyasal Madde ve Ürünler & 5,8 & 79,2 \\
\hline $\mathrm{CR}_{4}$ & B.Y.S. Makine ve Teçhizat & 4,7 & 87,4 & B.Y.S. Makine ve Teçhizat & 5,4 & 84,6 \\
\hline $\mathbf{C R}_{5}$ & Tarım ve Hayvancılık & 4,2 & 91,7 & Tarım ve Hayvancılık & 4,3 & 88,9 \\
\hline $\mathbf{C R}_{6}$ & Kâğıt ve Kâğıt Ürünleri & 2,8 & 94,5 & Radyo, TV, Haberleşme Cihazları & 2,4 & 91,3 \\
\hline $\mathrm{CR}_{7}$ & Kok Kömürü, Petrol Ürn., Nük. Yak. & 1,1 & 95,6 & Kâğıt ve Kâğıt Ürünleri & 1,9 & 93,2 \\
\hline $\mathbf{C R}_{\mathbf{8}}$ & Plastik ve Kauçuk Ürünleri & 0,8 & 96,4 & B.Y.S. Elektrikli Makina ve Cihazlar & 1,7 & 94,9 \\
\hline $\mathbf{C R}_{9}$ & Metal Eşya Sanayi & 0,7 & 97,1 & Ağaç ve Mantar Ürünleri & 1,2 & 96,1 \\
\hline $\mathrm{CR}_{10}$ & Ağaç ve Mantar Ürünleri & 0,6 & 97,7 & Plastik ve Kauçuk Ürünleri & 0,6 & 96,7 \\
\hline
\end{tabular}

Kaynak: TÜik, Dış Ticaret İstatistikleri

\subsection{Yoğunlaşma Katsayısı İle il Dış Ticaretinde Öne Çıkan Sektörler}

Yoğunlaşma analizi yapılırken, 2012-2016 dönemine ait dış ticaret verileri kullanılmış olup, öne çıkan sektörler hesaplanırken katsayının tüm yıllarda 1'in üstünde olması gerekliliği dikkate alınmıştır. Yoğunlaşma katsayılarının tamamı için, 1'in üzerindeki değerler sektörün Denizli'deki göreli üstünlüğünü (avantajını) ifade etmektedir. Buna göre Denizli ihracatına bakıldığında, yoğunlaşma katsayısı en yüksek sektör Tekstil Ürünleri sektörüdür. İlde diğer öne çıkan sektörler aşağıdaki tabloda verilmiştir.

Tablo 6: Denizli îhracatında Sektörlere Göre Yoğunlaşma Katsayıları

\begin{tabular}{|c|c|c|c|c|c|c|}
\hline Sektör Adı & 2012 & 2013 & 2014 & 2015 & 2016 & Ort. \\
\hline Tekstil Ürünleri & 3,80 & 3,14 & 3,35 & 3,47 & 4,01 & 3,55 \\
\hline B.Y.S. Elektrikli Makine ve Cihazlar & 2,67 & 2,57 & 2,94 & 3,98 & 2,80 & 2,99 \\
\hline Metalik OIm. Diğ. Mineral Ürünler & 2,02 & 2,01 & 2,24 & 2,41 & 2,65 & 2,27 \\
\hline Metal Eşya Sanayi & 2,14 & 1,84 & 1,55 & 1,40 & 1,45 & 1,68 \\
\hline Taşocakçılığı ve Diğer Madencilik & 1,19 & 1,70 & 1,77 & 1,62 & 2,09 & 1,67 \\
\hline Giyim Eşyası & 1,73 & 1,69 & 1,52 & 1,47 & 1,49 & 1,58 \\
\hline Ana Metal Sanayi & 1,04 & 1,79 & 1,77 & 1,21 & 1,14 & 1,39 \\
\hline Balıkçılık & & 0,69 & 0,83 & 0,79 & & 0,77 \\
\hline Maden Kömürü, Linyit ve Turb & & 0,05 & 0,01 & 0,00 & 2,09 & 0,54 \\
\hline Tarım ve Hayvancılık & 0,40 & 0,42 & 0,37 & 0,39 & 0,52 & 0,42 \\
\hline Gıda Ürünleri ve İçecek & 0,34 & 0,31 & 0,34 & 0,50 & 0,40 & 0,38 \\
\hline Kâğıt ve Kâğıt Ürünleri & 0,23 & 0,19 & 0,17 & 0,18 & 0,14 & 0,18 \\
\hline
\end{tabular}

Kaynak: TÜiK, Dış Ticaret İstatistikleri

Denizli ithalatında Ana Metal Sanayi, yoğunlaşma katsayısının en yüksek olduğu sektördür. Tekstil Ürünleri sektörü ise tıpkı ihracatta olduğu gibi ithalatta da yoğunlaşma katsayısının yüksek olduğu bir sektördür; öyle ki ikinci en yüksek yoğunlaşma katsayısına sahiptir. Denizli'de ithalatın yoğunlaştı̆̆ı diğer sektörler aşağıdaki tabloda verilmiştir.

Tablo 7: Denizli itthalatında Sektörlere Göre Yoğunlaşma Katsayıları

\begin{tabular}{|l|c|c|c|c|c|c|}
\hline Sektör Adı & 2012 & 2013 & 2014 & 2015 & 2016 \\
\hline Ana Metal Sanayi & 5,85 & 4,89 & 5,67 & 5,38 & 5,41 & 5,44 \\
\hline Tekstil Ürünleri & 4,79 & 4,84 & 4,73 & 4,65 & 5,23 & 4,85 \\
\hline Kâğıt ve Kâğıt Ürünleri & 1,90 & 2,20 & 1,66 & 1,55 & 1,09 \\
\hline
\end{tabular}




\begin{tabular}{|l|l|l|l|l|l|}
\hline Ağaç ve Mantar Ürünleri & 1,01 & 1,20 & 1,75 & 1,55 & 2,07 \\
\hline Tarım ve Hayvancılık & 1,38 & 0,03 & 1,39 & 1,78 & 1,24 \\
\hline Metalik Olm. Diğ. Mineral Ürünler & 0,51 & 0,49 & 0,58 & 0,53 & 0,54 \\
\hline B.Y.S. Makine ve Teçhizat & 0,54 & 0,50 & 0,66 & 0,39 \\
\hline Metalik Olm. Diğ. Mineral Ürünler & 0,51 & 0,49 & 0,58 & 0,53 & 0,51 \\
\hline B.Y.S. Makine ve Teçhizat & 0,54 & 0,50 & 0,66 & 0,39 \\
\hline Maden Kömürü, Linyit ve Turb & & & 0,52 \\
\hline B.Y.S. Elektrikli Makine ve Cihazlar & 0,12 & 0,29 & 0,74 & 0,51 \\
\hline Kimyasal Madde ve Ürünler & 0,45 & 0,33 & 0,33 & 0,54 \\
\hline
\end{tabular}

Kaynak: TÜiK, Dış Ticaret İstatistikleri

\section{SONUÇ}

Bu çalışmada 2012-2016 dönemi için Denizli ili dış ticaret verileri incelenmiştir. Türkiye toplam dış ticaretinin aksine Denizli ili dış ticaret fazlası vererek Türkiye'nin dış ticaret açığına olumlu katkı sağlamaktadır. Denizli dış ticareti ana sektörler itibariyle incelendiğinde hem ihracatta hem de ithalatta başı çeken sektörün imalât sanayii olduğu görülmektedir.

Hesaplanan yoğunlaşma oranları Denizli ihracat pazarının birkaç ülkeye bağlı olmadığını ve ithalat pazarının, ihracat pazarına göre daha dar olduğunu göstermektedir. İlde en çok ihracat yapılan ilk dört sektör, toplam il ihracatının \%76'sına karşılık gelmektedir; en çok ithalat yapılan ilk dört sektör, toplam il ithalatının \%85'ine karşılık gelmektedir. CR4 yoğunlaşma düzeyinin \%70'ten büyük olması çok yüksek derecede sektörel yoğunlaşma olduğunu göstermektedir.

Yoğunlaşma katsayısı ile il ihracat ve ithalatında öne çıkan ve uzmanlaşmanın söz konusu olduğu sektörler tespit edilmiştir. Buna göre il ihracatında öne çıkan sektörler; Tekstil Ürünleri, B.Y.S. Elektrikli Makine ve Cihazlar, Metalik Olm. Diğ. Mineral Ürünler, Metal Eşya Sanayi, Taşocakçılığı ve Diğer Madencilik, Giyim Eşyası ve Ana Metal Sanayii'dir. İthalatta öne çıkan sektörler; Ana Metal Sanayii, Tekstil Ürünleri, Kâğıt ve Kâğıt Ürünleri, Ağaç ve Mantar Ürünleri, Tarım ve Hayvancılık'tır.

Denizli'nin dış ticaretinde sektörel yoğunlaşmanın pazar yoğunlaşmasından daha yüksek olduğu görülmektedir. Sektörel yoğunlaşma eğer yoğunlaşılan sektörlerde gerçek bir uzmanlaşma olmasından ve bu sayede yüksek katma değerli üretim yapılmasından kaynaklanıyorsa olumsuz bir durum olarak değerlendirilmeyebilir. İlin üretim ve ihracat stratejisi belli sektörlerde katma değer artışı sağlanması üzerine kurulabileceği gibi üretim ve ihracatta sektör ve ürün çeşitliliğinin artırılması üzerine de kurulabilir. Özellikle kaynakların sınırlı olduğu durumlarda, kısa vadede, yoğunlaşmanın en yüksek olduğu sektörlere odaklanılması uygulanan stratejilerden daha hızlı sonuç alınmasını sağlayacaktır.

\section{KAYNAKÇA}

Bayraktutan, Y., Tüylüoğlu Ş., Özbilgin M. (2012). Lojistik Sektöründe Yoğunlaşma Analizi ve Lojistik Gelişmişlik Endeksi: Kocaeli Örneği. Uluslararası Alanya Işsletme Fakültesi Dergisi. 4(3): 61-71.

Çamlıca, Z., Akar, G., Şenkayas, H. (2016). TR32 Bölgesinin Lojistik Açıdan Analizi. Aydın Iktisat Fakültesi Dergisi. 1(2): 73-88.

Erkan, B. \& Sunay, Z. Fatih (2016). Türkiye'nin İhracatının Yoğunlaşma Perspektifinde Analizi. Insan ve Toplum Bilimleri Araştırmaları.

GEKA (T.C. Güney Ege Kalkınma Ajansı) (2018). Aydın Serbest Bölgesi Fizibilite Etüdü. Yayınlanmamış Rapor, 76-83.

İskenderoğlu, Ö. , Gülseren, M . (2017). Bölgesel Kalkınmada Etkili Faktörlerin Yoğunlaşma Katsayısı İle İncelenmesi: Niğde illi Örneği. Nevşehir Hacı Bektaş Veli Üniversitesi SBE Dergisi. 7 (2): 18-34.

Kaynak, S. \& Ari, Y. Onur (2011). Türk Otomotiv Sektöründe Yoğunlaşma: Binek ve Hafif Ticari Araçlar Üzerine Bir Uygulama. Ekonomik Yaklaşım. 22(80): 39-58.

Sungur, O. (2015). TR61 (Antalya, Isparta, Burdur) Bölgesinde Sektörel Yoğunlaşmanın ve Yoğunlaşma Dinamiklerinin Analizi. Yönetim ve Ekonomi Araştırmaları Dergisi. 13(3): 316-341. DOI: 10.11611/JMER695

TÜiK (Türkiye İstatistik Kurumu). Dış Ticaret İstatistikleri. http://tuik.gov.tr/UstMenu.do?metod=kategorist. Erişim: 22.08.2018 